\title{
Hydroxyethyl starch (HES) utilization before and after a regulatory safety warning
}

\author{
Christopher L. Pysyk, MD - Sylvain Boet, MD • Manoj Lalu, MD • \\ Alan J. Forster, MD • Gregory L. Bryson, MD
}

Received: 20 February 2018/Revised: 6 March 2018/Accepted: 6 March 2018/Published online: 25 October 2018

(c) Canadian Anesthesiologists' Society 2018

\section{To the Editor,}

Use of hydroxyethyl starch (HES) has come under scrutiny as accumulating evidence has suggested that HES fluids are associated with an increased risk of acute kidney injury and death among the critically ill. ${ }^{1}$ These findings prompted Canadian $^{2}$ and international regulators to issue warnings from 13 June 2013 to 18 July 2013 regarding the use of HES products. Regulatory warnings were widely discussed amongst our department membership at the time. We wished to determine the effect of these warnings on HES use in the operating rooms (OR) of The Ottawa Hospital (TOH), a tertiary care academic health sciences centre in Ontario, Canada.

Following approval of the Ottawa Health Sciences Network Research Ethics Board (\#20140637, submitted September 2014), we performed an observational historical cohort study of patients undergoing both elective and emergency surgeries at $\mathrm{TOH}$. We planned to use our anesthesia information management system to link HES exposure to postoperative outcomes. Variable fluid

This letter is accompanied by an editorial. Please see Can J Anesth 2018; 65: this issue.

C. L. Pysyk, MD $(\bowtie) \cdot S$. Boet, MD · M. Lalu, MD

Department of Anesthesiology and Pain Medicine, The Ottawa

Hospital, University of Ottawa, Ottawa, Canada

e-mail: cpysyk@toh.ca

\section{A. J. Forster, MD}

Department of Medicine, Ottawa Hospital Research Institute,

The Ottawa Hospital, University of Ottawa, Ottawa, Canada

G. L. Bryson, MD

Clinical Epidemiology Program, Department of Anesthesiology and Pain Medicine, Ottawa Hospital Research Institute,

University of Ottawa, Ottawa, ON, Canada documentation practices in our electronic medical record precluded accurate quantification of HES exposure in individual patient data. As HES products were stocked on anesthesia drug carts and in our OR pharmacy, we were also unable to use individual patient prescription records to define exposure. We instead turned our attention to systemwide use of HES as determined by the quantity of such products ordered. Order records of HES arriving to the OR were obtained from the Logistical Services and Purchasing Department of our hospital. Given that any HES-containing product available to the OR was exclusively managed through the Logistical Services and Purchasing Department, we assumed that HES products dispensed to the OR were a reasonable surrogate for the volume of HES products administered to patients in the OR. We studied monthly ordering practices for the six-month period before the regulatory warnings (1 January to 30 June 2013) and then for 42 months after the warnings (until December 2016).

The Figure shows monthly totals of HES-containing fluids ordered to the OR from January 2013 to December 2016. From 1 January to 30 June 2013, the average number of HES-containing fluids ordered to the OR was 380 units per month. In the six months following the HES warnings in June/July 2013, an average of 74 units of HES per month were ordered to the OR marking an $81 \%$ drop in HES product ordering. Based on published cost of HES solutions in $\mathrm{Canada}^{3}$ this change in HES ordering practice saved our institution over CDN \$200,000 per year.

We noted persistent HES use that exceeded 40 units per month throughout 2014, the year after regulatory warnings. In conjunction with a separate quality improvement initiative to standardize anesthesia drug cart contents, HES products were removed from the anesthesia drug carts and placed in the OR pharmacy. Following this change 


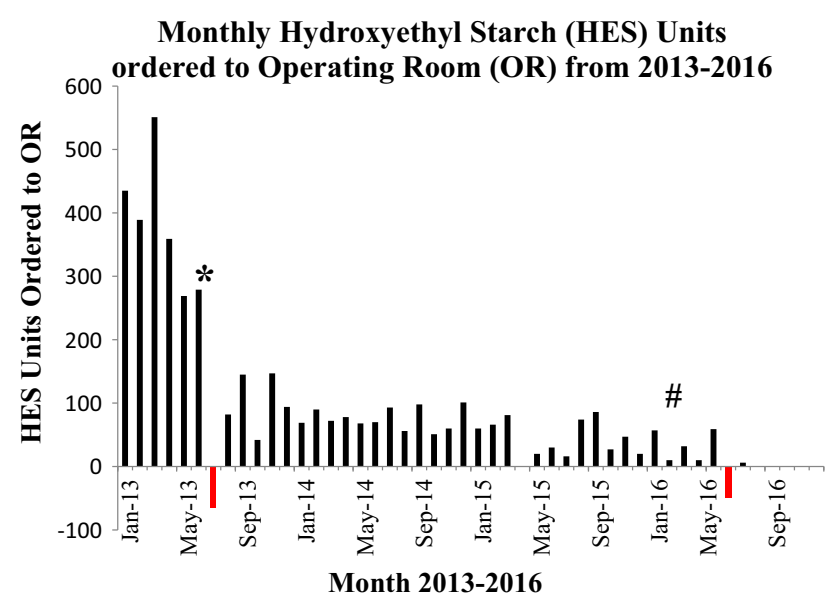

Figure Monthly number of hydroxyethyl starch (HES) units ordered to the operating room (OR) from 2013-2016. Negative (red) bars denote return of HES to the purchasing division of the hospital. No bar equals zero HES units ordered to the OR for that month. *Regulatory HES warnings June-July 2013; \#anesthesia cart redesign with HES removed

(Figure) to remove HES from the anesthesia OR drug carts, monthly HES ordering dropped to and was sustained at $<1 \%$ of pre-warning levels.

Research evaluating a variety of interventions indicates that it may take up to 17 years for evidence to change practice. ${ }^{4}$ Half of this time is spent in the implementation of established evidence. Our experience suggests that equipment re-design to force function behavior (e.g., removal of HES from anesthesia cart) may be required to bring about system change once messaging and education have been tried. ${ }^{5}$

Acknowledgements Drs. Colleen McFaul, Lauralyn McIntyre, and Monica Taljaard contributed to the original conceptual design of the study and ethics submission. Dr. Daniel McIsaac championed HES removal from the anesthesia drug cart. Mr. Tobin Hess assisted with purchasing and ordering data for hydroxyethyl starch provided to the operating room. Drs. Boet and Lalu were supported by The Ottawa Hospital Anesthesia Alternate Funds Association. Dr. Boet was also supported by the Canadian Anesthesia Research Foundation through the Canadian Anesthesiologists' Society Career Scientist Award in Anesthesia.

Conflicts of interest None declared.

Editorial responsibility This submission was handled by Dr. Hilary P. Grocott, Editor-in-Chief, Canadian Journal of Anesthesia.

\section{References}

1. Zarychanski R, Abou-Setta AM, Turgeon AF, et al. Association of hydroxyethyl starch administration with mortality and acute kidney injury in critically ill patients requiring volume resuscitation: a systematic review and meta-analysis. JAMA 2013; 309: 678-88.

2. Health Canada. Recalls and safety alerts. Voluven and volulyte (hydroxyethyl starch (HES)) - increased mortality and severe renal injury - notice to hospitals. Available from http://www. healthycanadians.gc.ca/recall-alert-rappel-avis/hc-sc/2013/ 34697a-eng.php (accessed March 2018).

3. Callum JL, Lin Y, Pinkerton PH, et al. Bloody Easy 3: Blood Transfusions, Blood Alternatives and Transfusion Reactions: A Guide to Transfusion Medicine - Third Edition. Ontario Regional Blood Coordinating Network; 2011.

4. Balas EA, Boren SA. Managing clinical knowledge for health care improvement. In: Bemmel J, McCray AT, editors. Yearbook of Medical Informatics 2000: Patient-Centered Systems. Stuttgart, Germany: Schattauer Verlagsgesellschaft mbH; 2000. p. 65-70.

5. Trbovich $P$, Shojania $K G$. Root-cause analysis: swatting at mosquitoes versus draining the swamp. BMJ Qual Saf 2017; 26: 350-3. 